\title{
Facing Reality and Challenge Making Course Selection System Become the Leading Reform in Chinese Vocational Colleges
}

$\mathrm{Hu} \mathrm{Yi}$

Department of Music, Professional Arts Institute of Hubei, Wuhan, Hubei, China (7020583@qq.com)

\begin{abstract}
- this paper first introduces the teaching characteristics for vocational colleges at home and abroad based on elective system, talent training, and course content. And then three considerations for vocational college curriculum management are introduced. The advantages of the vocational college curriculum should be embodied in serving society and arousing the enthusiasm of both the teachers and students. Features of the elective system are analyzed in vocational colleges suggesting that the curriculum management should break the empirical thinking, grasp the situation in time and guide student's course selections. Finally, the method and implementation for elective system is presented which means that the enhancement of the elective system should be long-term perspective and workable, the implementation should be practiced seriously and the trouble we meet should be feedback in time for solving.
\end{abstract}

Keywords - course selection, teaching, talent cultivation

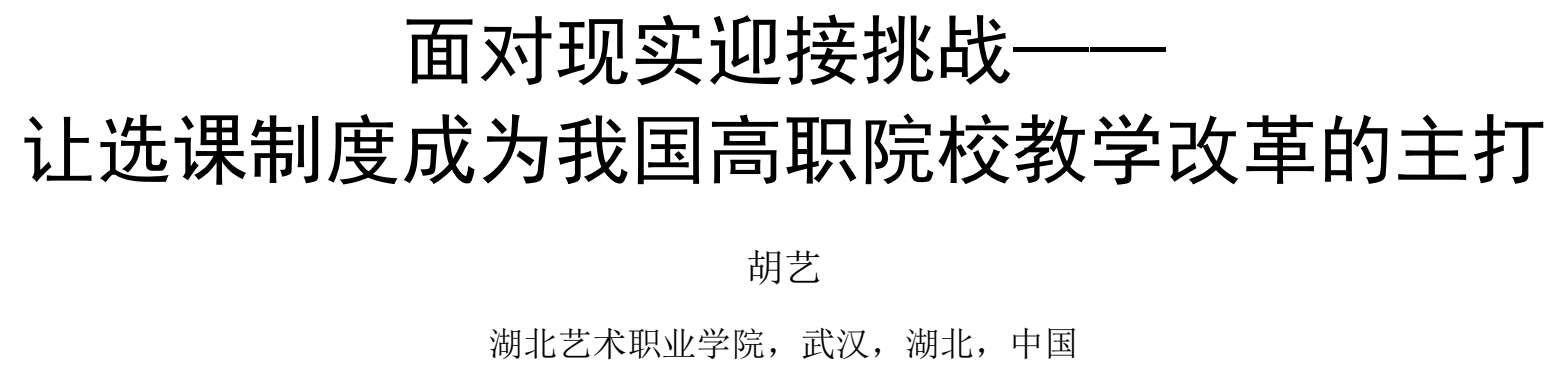

摘 要 本文首先从选课制度、人才培养、课堂内容等面介绍了国外大学教学的特点, 随后引入我国高职课程管理的三点思考。 高职院的选课优势应体现在更加贴切服务于社会、老师和学生积极性能充分调动等方面。分析了高职院校选课制度的特点, 提出在选 课管理方面, 要打破经验思维, 深入一线及时掌握情况, 辅助引导学生正确选课。最后, 提出了完善选课制度的手段及实施方法, 即 选课制度的实施要统御全局、着眼长远、方案要切实可行; 制定的实施措施要脚踏实地, 认真实践; 遇见问题要及时反馈, 不断反思, 及时纠正问题。

关键词 选课, 教学, 人才培养

1. 引言

职院校作为职业人才市场的 “预备役”, 肩负着培养高 素质技能型人才，保持整个社会经济系统中人力资源结构 的稳定性, 促进社会流动和社会有效运转的重任。因而职 业教育的核心任务是围绕社会对人才的动态需求, 把学生 培养成适应工作变化的知识型、发展型高技能人才。

怎样才能让我校这一类的高职院校, 快速适应这一要 求, 早出人才、快出人才、多出人才呢?

我的理解是: 必须面对现实, 迎接挑战, 大胆进行教
学制度的改革。因为, 教学是学校的中心工作, 教学朝着 适应社会需求的方向改变了, 朝着早出人才、快出人才、 多出人才的目标改变了, 学校就有了竞争力和旺盛的生命 力, 就会欣欣向荣不断发展壮大。

高校的教学改革是多方面的, 但选课制度理所当然是 其最重要一环。因此, 让选课制度成为我校教学改革的主 打, 才是最好的出路。

根据以上要求, 谈几点自己的想法。 


\section{2. 国内外大学教学的特点}

2.1 国外大学教学的主要特点

\section{特点一：选修是方向}

选课制度, 也称课程选修制, 简称选课制。即允许学 生对学校所开设的课程有一定的选择自由, 包括选择课程、 任课教师和上课时间, 选择适合自己的学习量和学习进程, 来让自己在相同的时间内, 学到更多更好的知识。

大学课程, 一般分为必修课和选修课。必修课是指学 生必须修习的课程, 一般是指基础性的知识; 这一点, 学 校一般有统一的要求和安排。选修课是指根据学生个人, 根据自己的兴趣或专业需要, 去自由选择修习的课程; 指 的是有些知识不是基础性的, 是与兴趣和研究方向有关的, 这部分知识学校没有硬性规定, 可以自由选择。

国际上, 尤其是发达国家的高校教学改革, 几乎都在 采用选课制, 大力增加选修课程, 使学生毕业后在市场上 具有竞争能力。鼓励和要求学生进行跨专业、跨学科选课, 让学生拓宽知识面, 增强适应性。有资料显示, 这些国家 的高职学生选修课程, 其学时占到了总学分的 $1 / 2$ 到 $2 / 3$ 。 这一有效手段, 来加速本国人才的培养。

法国: 非常重视课程选修, 将学生学习的必修课作为 硬指标进行强制性规定, 并在必修课中加强了专业基础知 识课程; 同时, 将学生学习的选修课作为软指标划定范围, 把大学的实践课程形式固定下来。这一范围十分广泛, 学 生拥有较大的择课自主权, 既可以在本学科专业范围内选 修, 也可以跨学科专业选修。学生只有达到规定的必修课 与选修课的相应学时, 才能授予学生相应的毕业文凭。

英国: 高职选修课的建设, 是根据学生所学专业, 在 学生学习期间, 一般安排 1 年左右的时间, 到工商企业界 从事实践活动。

之所以产生这种现象, 是因为经济的增长带来了职业 变换的频繁, 据统计, 美国人平均每五年更换一次职业, 其终生学习体系较完善, 学生在大学毕业后仍可返回校园 或在工作单位附设的继续教育机构, 修习有关课程, 形成 新的知识结构。由此看来, 选修课的定位, 其首要任务是 以培养职业人才为主线, 其培养方法和办学目标是围绕 “以服务为宗旨, 以就业为导向”, 去培养区域建设所需的 高素质技能型人才。在此办学思想指导下, 将公共选修课 课程目标定位在对专业课程的补充和延展上, 对学生职业 意识与职业能力的培养, 对当今信息技术、区域经济动态 和相关交叉学科的及时介绍, 以致最终实现拓宽学生的知 识面, 优化学生的知识结构, 增强学生的理性思维能力和 技能专业应用、以及适应岗位的能力性为目的。

\section{特点二：通才是趋势}

当前, 许多国家的高等教育, 紧跟知识更新的速度, 完善学生的知识结构, 拓宽学生的知识, 从深化学生的基 础理论和实际操作能力出发, 来满足学生毕业后谋职的需 要; 都普遍认识到, “专家” 对社会固然重要, 但 “通才” 则更是社会需要。其表现为: 她们不仅注重 “专业人才的 培养”, 而且一种新的趋势, 即 “通才培养” 正在开始兴起。 其表现为:

一是在理论教学上, 对学生实行跨学科跨专业的教育, 已达到扩大视野扩大知识面, 提高综合素质的目的。 美国高等学校有通才教育的传统, 其培养的人绝大多数是 在某一领域、学术略有所长的通才; 日本在第二次大战后学 习了美国高等教育的之一模式, 强化了通才教育, 使其成 为了日本经济得以腾飞的原因之一。

二是理论与实践相结合, 把理论知识转化为实际能力, 已达到学以致用的目的。这方面如美国的 “通才教育”。近 年来, 特别提出了 “合作教育--加强高校与企业的产学结 合”。

日本的 “通才教育”。大学的课程采取讲课、实验、实 习、课堂讨论和实地技术操作等方式, 或单项进行, 或几 种课程形式并用。

德国的 “通才教育”。一些高等学校在录取新生时, 就 附加学生有无实践经验的规定, 并在高等教育中多种课程 方式并举。

\section{特点三: 讨论进课堂}

另外, 国际上许多国家, 还非常注重讨论课的实施, 以此来强化学生的思维能力、表达能力和动手能力, 做到 了对学生的全面培养。

讨论是培养学生思维能力、表达能力、组织能力和创 造性的一种有效方式。在教学中, 引进讨论的方法, 实行 师生互动、学生互动, 不仅改变了满堂灌的填鸭式教学方 式, 使单向灌输的被动教育, 变成双向交融的互动教育; 而且, 能极大限度的调动师生的积极性, 强化了师生应变 能力的提升和信息量的扩大, 因为讨论中, 学生带来的一 些新问题新见解, 促使教师必须离开教材, 进行快速思考 和回答; 反过来, 教师的回答又促使学生从新的角度思考, 回答甚至争论, 从而提升了师生的能力。

\section{2 我国高职课程管理的启示}

特点一、注重基础理论知识的强化。我国的高职教育, 相对于发达国家来说, 由于起步较晚, 教学方法, 普遍采 取的还是沿用我国普通高校的教学方法, 即注重基础理论 知识的强化。这种教学方法的优势是, 强化了理论思维的 
提升, 使我们的学生, 相对于其他国家的学生来说, 在这 方面卓显其长。但是, 这种教学方式也有自身的不足, 明 显存在只着重于 “心” 或 “脑” 的训练, 而忽视了对 “手” 的训练; 加之受本民族传统文化的影响, 比如儒学中 “劳 心者治人, 劳力者治于人” 的教育, 学生往往远离实际, 变成了 “君子动口不动手” 的 “闲人”。又如教学中的 “灌 输式” 教育等等, 更使学生成了被动的接受者。致使我们 的高职教育一时难以突破巢臼。

特点二、有了国外经验的引进。自从西学渐进后, 国 外一些先进的教学方法开始进入中国; 特别是改革开放以 来, 国际上一些崭新的教学方式不断地引进。

我们的教育方式有了明显的变化, 比如实验法教学、 体验式教学等等, 使高校学生不仅注重理论修养, 而且更 注重实际历练了。有效的强化了学生理论思维和解决实际 问题的能力。

特点三、新的教学方法的尝试。近年来, 随着高职教 育的不断深化, 全国数百所高职学院的教师, 不断进行探 索, 一些新的教育方式不断涌现, 中国特色的高职教育体 系正在兴起。诸如 “通才” 和 “专才” 教育相结合、研讨 式教学方法等等方法, 正在兴起。

上述各种教学方法, 冉庸置疑, 虽然, 都各有其优势 和不足, 但在实际操作中, 最使人感到欣慰的是选课制度 的引进和产生, 给高职院校的教学带来了更多的新鲜空气, 宽化了学生的视野, 调动了学生的积极性和自觉性, 有效 的加速了学生能力的培养。

\section{3. 高职院选课制度的优势}

从实践效果和现实意义的角度来看, 高职院选课制度 的优势体现在三个有利于上。

\section{1 有利于为社会培养人才}

实践证明, 选课制度, 从教学方法来看, 是一种先进 文化和科学方法; 从教学效果来看, 也是一种先进的生产 力, 是培育人才的一种正能量。只要我们在实践中把握好, 它将为社会培养人才, 增加新的活力, 起着一个加速器的 作用。

理由一、变 “包办代替” 为 “物择天竟”。人才的培养, 除了个人的努力这一内在条件外, 外部的条件也是极为重 要的。选课制度的产生, 就是这种有效的外部条件之一。 过去, 学生的课程, 基本上, 都是由教务部门按专业、按 学期定的。这种方法, 虽有其合理性, 但却忽视了学生的 个性, 不利于 “人人出彩”, 学生学习就像父母 “包办婚姻” 一样, 不问对象不问青红㿝白得一律接受。压抑了思想没 有自由, 违背了人才培育的规律。有了选课制度后, 等于
为人才成长提供了一条 “物择天竟” 的道路, 学校给学生 提供了广阔的新的空间, 可以让学生自由敗翔。

理由二、变 “一成不变” 为 “各取所需”。过去, 学生 的学习, 不仅要完完全全按照规定的课程不折不扣的执行 外, 而且在时间、教师、教室、教材等方面, 也形成了一 种 “一成不变” 的模式。“教”与 “学”、“师”与 “生” “人” 与 “物” 等等之间, 至少是半年的固化状态, 难以闻到新 的空气。选课制度, 对于高校人才培养来说, 可谓有了质 的飞跃, 为教学改革寻找到了新的契合点, 改变了昔日那 种 “一成不变” 的固化模式, 形成了新的 “各取所需” 的 “教”与 “学” “师”与 “生” “人”与 “物” 的新的富有 生命力的格局。

理由三、变 “计划机制” 为 “市场机制”。选课制的产 生, 等于在教室里引进了市场机制, 能让学生获得更高质 量的教育。不问客观实际, 不按事情变化, 一切都按个人 意愿而 “闭门造车” 的 “计划机制”, 对于信息高度发达的 今日高校学生来说, 已经过时。更何况大学生一般都有较 好的鉴别力, 他们不愿将把宝贵的时间花去听索然无味的 讲课; 同时, 自己付费上大学, 就会像购物者付费淘宝一 样, 希望获得好的教育。因此, 自主选课, 将是高校学生 修习的一种追求了。另外, 高校学生在校接受教育, 是一 种双向的关系, 即教与学的关系, 其中的 “教”, 当然是教 师 (包括其人格魅力、能力素质等等)、教材、教育设施、 教学的方式方法等等; “学”, 就是学生、学习内容、学习 的方式方法等等了。在这种双向关系中, 首要的当然是人 的关系了, 简而言之即师生关系。选课制度的现实意义和 实际价值, 就是优化了师生资源配置的一种市场机制。

\section{2 有利于调动老师的积极性}

作为传道授业的教师来说, “传道” 就是教育学生掌握 高尚的品德, 先进的思想等等, 狭义的理解那就是为人师 表了; “授业” 就是将先进的知识文化及技艺, 传给学生, 让学生掌握一定的技能本领, 有回报社会和自己建功立业 的立身之本。在这里, 教师的根本职责是注重于 “传”。

一般说来, 绝大多数教师都是愿意将人类社会的先进 思想、先进文化和知识不遗余力传授给学生的; 当然, 绝 大多数学生也是愿积极接受教育, 不断提升自己的。但是, 社会上往往有一种现象, 有的老师自身的素质不错、教学 中下的功夫不少, 但学生却不满意, 学的东西不扎实, 甚 至听不懂、不愿听, 乃至逃课等等。这是什么原因呢?

通过观察, 我发现, 这就是一个 “无的放矢, 文不对 题” 的原因, 也就是说, 老师讲的课程是学生不愿意接受, 或者是一时难以接受的知识; 就好像一个英语老师, 给专 修日语的学生讲课一样, 即使这个老师是世界一流的英语 
专家, 具有世界一流的教学水平, 但专修日语的学生就是 再努力, 一时半载也无法英语教师传授的知识; 何况还有 许多其他原因, 所以, 这样的教学效果怎么能够得到知音 呢? 怎么能够收到理想结果和调动教师的积极性呢?

由此出发, 我们可以得出一个结论, 选课制度, 恰好 是调动教师积极性的一条极好途径。因为它优化了资源配 置, 采取合并同类项的方法, 将相同专业或者相类似专业 的师生, 组合到一起, 达到同气相求的效果, 让教者教有 知音, 学者学有追求, 共同步入佳境, 达到两全其美的效 果, 这样的课程, 不仅满足了学生的需求, 而且会大大调 动老师的积极性。

对于老师来说, 选修课还有一个好处, 可称为 “自由 市场效应”, 老同学会给你介绍经验说, 某某教授好说话, 选他的课可得高分, 不费力气。这样学生通过选修课能得 以主动地调配学习精力, 毕竟一个人的精力是有限的, 在 每门课上都花费同样大的力气不仅自己很累, 还有可能落 得啥都都学不好的结果, 而且你还会因此而失去很多生活 乐趣。同时, 也会在教师中形成了一种积极的竞争机制, 让教师积极充电, 强化学习, 不断更新知识, 以满足学生 的需求。

\section{3 有利于调动学生的积极性}

作为学生来说, 她们的根本职责当然就是 “学” 了。 事物都是有个体差异的, 世界上找不到两片相同的树叶, 每个学生都有自己的兴趣和爱好, 有每个学生的素质能力, 即使是具有共同追求共同兴趣和爱好的学生, 也还有其他 方面的差异。

选课制度, 正好可以调动学生的积极性。学生通过自 己的爱好、兴趣以及自己的专业程度, 去寻找自己要找的 老师和课程, 找到自己追求的目标、正确的途径以及想学 习的知识。这样就可以让学生自觉地学, 想方设法的学; 这种方法, 比我们那种不问个体差异, 一味按照越组代庖 式的安排课程和 “拉郎配” 的教学方式, 不管你适不适应, 接不接受得了, 只要教室里座无虚席, 即使大家都䟜在桌 子上睡觉的教学, 显然, 其实际效果要好得多, 其现实价 值要先进得多。

实际上, 很多人并不是很早就能认识到自己的专长之 所在, 因此, 在作出最后决定之前, 一般都有一个摸索与 尝试的阶段。资料显示, 在北京大学, 因选修了非本专业 的一门课程而对这个专业产生兴趣, 继而继续深造 (在国 内或去国外读研究生）的事例并不少见。因此, 在初入高 等学府面临无数选择时先采取开放的态度, 面向知识海洋 多开几个窗口, 大胆尝试, 待明确方向后再下功夫钻研, 会更有成就。
另外, 年轻人的爱好和长处是多种多样、各不相同的。 对他们的教育, 应该是因材施教、因势利导, 尽可能使他 们每个人的爱好和长处得以充分发展。若用一套课程把不 同爱好、不同长处的学生捆在一起学习, 这样做的结果常 常是爱之实足害之无穷, 使许多学生的爱好、长处被抑制、 被伤害。而选课制允许学生根据自己的兴趣、爱好、才能、 学习程度, 各取所需, 具有很大的灵活性, 使学生的爱好 和长处得以迅速成长和较好发挥。可以说, 承认学生个性 差异, 尊重学生个性发展, 是选课制被接受并受到青睐的 最根本原因。它给了学生对于学什么学以很大的自主权。 当然, 不能说每个学生都能很好地、充分地利用选课制的 优点, 但只要这种制度存在, 任何学生都有可能得到成才 的最好机会。

上述三个方面, 从根上讲, 就是对科学发展观的忠实 践行, 就是以人为本的极好体现。她在尊重学生个性发展 的基础上, 要求我们的教学安排, 要适应个别差异、因材 施教, 要求我们的教学要创设相应的情境, 建构相应的课 程知识体系以及建立相应的评价制度。由此看来, 选课制 度的实行, 对教育体制的革新和教学质量的提高以及学生 的全面发展都具有重要, 是一种让师生人人都能出彩的好 方法好制度。

\section{4. 选课制度需注意的事项}

大学实行选课制度, 它的现实意义和实际价值和利益, 已经十分明显, 但是实行起来, 并不那么容易, 它需要我 们解决几大问题, 扫除几个障碍。

\section{1 是习惯思维,需要彻底改变}

若真正要实行选课制度, 我们就必须要打破昔日那种 传统的教学模式和教学方法了, 这就需要我们彻底的改变 旧的观念, 适应新的形势, 创造性的迎接新的挑战。

首先, 课堂出现的常常会是陌生面孔。昔日的课程都 由教务部统一安排好, 然后由学校集中时间集中地点指定 任课老师授课。采取了选课制度后, 学生则可以在自己专 长的范围内, 根据自己的特长和兴趣来选择课程。部分公 共选修还可以跨专业进行选修, 以拓宽自己的知识面来提 高自己的能力。从某种意义上讲, 自由氛围就格外突出, 师生常见的就不再是半年一定的熟悉面孔了, 而是经常变 化的陌生面孔。这样一来, 对于教师们来说, 由于学生的 变化太大, 掌握的信息量就要求更多更深更精了, 所以, 迫使教师面对现实, 改变习惯思维。

其二, 班级固定的教室会是流动教室。选课制度对于 学生来说, 过去每半年一定或多年一定的教室, 也发生了 变化, 而变成流动性的听课; 也就是说, 随着每个学生的 
不同选择, 这节课在 A 教师, 下节课就可能在 B 教室了。 这就要求学生要适应变化, 及时掌握变化的信息, 能正确 的按时到达上课地点。

其三, 知识更新的时代会是一种压力。选课制度的实 行, 无论是对必修课程还是对选修课程来说, 教师面对的 学生, 其水平则可能是参差不齐的, 说不定某门课程同时 有大一、大二、大三等几个年级的学生挤在一起来听, 对 于不同层次的听众, 教师就强化自己加强知识更新, 找到 大家都能接受的传授方法和都能掌握的知识结构, 这对于 教师来说是一种较大的压力。尤其是遇到一些学生的特别 性提问, 还会令教师一时难以准确回答。

\section{2 深入一线, 及时掌握情况}

选课制度的产生, 将会打破原有的传统的教学形式, 形成一种全新的格局。这就要求校方的管理层要深入一线, 及时掌握各种情况, 特别是一些不可测的因素, 去不断进 行微调。

首先, 要了解学生。选课制度产生后, 有的课程可能 会遇到听众很多甚至人山人海的局面, 这样一来, 既会造 成人气极旺的课堂气氛, 也会带来过道堵塞秩序不佳的可 能, 甚至安全事故等; 同时, 有的课程也可能会门临冷落 车马稀, 这样也会浪费资源。所以, 校方要及时深入到学 生中, 了解每堂课的受众量, 快速拿出应变方案以预防不 测。

其二, 要了解老师。选课制度的产生, 对老师是一个 新的考验, 综合素质高、业务能力强、知识面广信息量大、 表达能力强的教授来说, 正是其大显身手的时候。而对于 个别能力不强, 或者是刚走上工作岗位的教师来说, 则是 一场严峻的考验。这就要求管理层, 要了解每个教师的优 缺点, 知人善任扬长避短, 恰到好处的用好每个教师。

\section{3 教学管理, 将会更加严格}

选课制有利于促进现代化教学手段的形成。选课制给 予学生充分自主权, 学习的局面不再单一, 学籍和教务管 理人员的工作量会成倍增加, 学年制管理的手段无法适应 选课制管理要求。因此, 学院必须与时俱进, 不断改革, 以适应形式的发展, 从教学管理来看, 建立、健全一套新 的、完整的教学管理体制, 运用现代化科技手段, 使学院 的教学管理程序化、制度规范化、质量标准化将是当务之 急。

\section{4 有效把握, 注意盲目选课}

选课制度是合理的科学的, 但在实行中, 由于知识的
或认识的差异等种种原因, 学生所选的课程, 也有不一定 准确的现象, 有的可能 “文不对题”, 有的可能 “张冠李戴” 等等, 对于这种情况, 学校要有预警机制、导航机制等。 预警机制主要是要提醒学生, 不要对课程望文生义, 一叶 障目以造成乱选、误选现象。导航机制就是要给不同专业 的选课, 有个基本的勾画, 给学生以指导, 以免学生盲人 摸象。

\section{5. 实施途径以及相关对策}

选课制度, 对于我校教学来说, 将会是一场不可避免 的改革, 是每个教师必须面对的一个严峻挑战, 我们不可有 丝毫的解急或侥幸心理。以它发展的趋势来看, 从其产生 之日起至今, 一直保存着旺盛的生命力。当前, 不仅风行 于国际同时也风行于国内各高校, 甚至还进入了中专教学。 这是一种造就人才深受社会欢迎的好方法, 谁先接受这种 教学方法, 谁就会尝到甜头得到好处。

作为湖北艺术职业学院, 若要使这一教学方式实施得 更顺利更完善一下的话, 建议从如下方面去把握。

\section{1 要统御全局, 着眼长远, 拿出切实可行的实施方案}

首先, 我们要统御全局。选课制度, 对于学校的工作 来说只是其中一个点位, 但这可不是个寻常的点位, 从某 个方面来讲, 它是牵一发而动全身的。因为, 教学是学校 工作的中心, 教学方式的改变, 必然会车动学校的其他工 作, 甚至会改变整个教学模式, 形成新的教学格局。由此 出发, 便会产生打破传统的师资安排, 教学布局等等。所 以, 建议学校高屋建領, 从全局着眼来部署这一工作。

其二, 我们要着眼长远。选课制度, 是一个不断完善 不断发展的渐进式工作, 今天的成果, 只能说明今天的方 法是正确的, 并不意味着明天还会取得胜利, 一句话不会 一劳永逸, 当常胜将军; 在未来的教学中, 选课制度还需 要我们与时俱进不断丰富。所以, 我们更要立足长远, 去 研究新问题, 做出新成绩来。

从这两点出发制定战略方案, 使学校的选课制度, 按 照确定的方向, 一步步走向成熟。

\section{2 要脚踏实地, 认真实践, 制定行之有效的实施措施}

首先, 要根据专业知识结构、学生个性发展需要和市 场对人才的需求情况, 对某一大类专业的课程进行整体规 划, 确定出必修课的种类、数量以及必须修满的学分数。

其次, 在学分的计算上, 要体现出考试成绩和课程在 整个课程体系中, 所占的权重, 比如, 可以这样设计:实际 学分数 $=$ 规定学分数 $\mathrm{x}$ 成绩 $(\%) \mathrm{x}$ 权重。

其三, 打破专业间的壁垒, 允许学生跨专业、跨系选 
修其他的课程。

其四, 加大选修课的课程门类, 内容应涉及人文学科、 体育学科乃至边缘学科、交叉学科、新兴学科等。

其五, 要建立科学合理的公共选修课课程体系

选修课和必修课是不同的课程模块, 在构建学生的知 识结构、能力结构和素质结构方而均发挥不同作用, 不应 该有主副课程之分, 应当把选修课作为一项重要而系统的 课程体系加以建设。在设计公共选修课课程体系时, 以实 现公共选修课的整体教学目标为基本原则, 立足社会、职 业和学生的需求, 重在丰富和拓宽选修课的日程, 为教师 开课和学生选课提供参考。笔者通过对现有选修课进行整 合, 针对社会需要和个体需求, 以一个模块的形式初步设 计出公共选修课课程体系, 类别划分相对细化, 便于指导 教师开课。在具体的选修课课程设置时, 要和整体教学计 划与现有教学相统筹, 教学内容可针对高职学生的实际基 础适当降低难度, 在教学方法和方式上要有所创新, 有利 于激发学生兴趣, 指导学生选课。

其六, 高职院公共选修课的师资存在较大的不合理 性。从各高职院来看, 开选修课的多是初、中级职称教师, 高级职称教师们不需要开公共选修课。有的开课教师片面 认为选修课非主要课程, 没有必要做精心的准备和教学, 再加之学院对选修课教学管理不善, 教学班人数多, 课酬 低, 影响了教师开课上课的积极性, 使得选修课课堂管理 不严, 教学质量不高, 教学效果不好。对此, 高职院应重 视挖掘师资潜力, 建立一支相对稳定的公共选修课教师队 伍。

这一方面, 可以根据教师的专业特点和学科发展方向, 鼓励有能力的教师, 特别是副高以上的教师开设高质量的
选修课, 并做到选修课与必修课的待遇相等, 以激发教师 的积极性。对一些重要的选修课也可采取培训方式, 提高 公共选修课教师的素质。

5.3 要及时反馈, 不断反思, 查找不足以及时纠正问题

选课制度, 对于我校来说, 尚处于开始阶段, 没有经 验, 需要我们一步步的探索、认识和总结; 所以, 我们要 保持一种既开放又谨慎的态度来操作。在具体的操作中不 断的反馈信息, 反思自己的不足, 发现问题及时纠正, 使 这一工作日臻成熟。

\section{6. 结束语}

总而言之, 选课制度, 是高校教学中的一种颇富科学 性的教学方法, 是一条科学培育人才的道路, 只要我们积 极接受乐于推广, 并在实践中谨慎运作, 这条路一定会让 我校的教学工作, 越走越宽广, 越走越光明。

\section{参考文献(References)}

[1] He Kekang. "The theory of modern education technology and the deepening education reform" J, China Education Info, 2001(6), pp: 3-12.

[2] Wang Yuqiong. "Considerations of the Management of University Public Elective Courses" J, Teacher Education Research, 2005(3), pp: 50-63.

[3] Chen Lian, Sun Hui. "Public Elective Courses Setting for Reference" J, Forum on Contemporary Education, 2009(2), pp: 24-26. 